\title{
Practice-based Research Networks at the Crossroads of Research Translation
}

\author{
Zsolt Nagykaldi, PhD
}

Practice-based research networks (PBRNs) are "experimental farms" for research that matters in clinical practice. One of the defining characteristics of PBRNs is their ability to operate across a wide range of the bidirectional "pipeline of research translation," from clinical trials to informing health care policy. Developing effective translational approaches requires significant experimentation with new or innovatively combined research methods and theoretical frameworks. While the first decades of PBRN research generated a substantial body of evidence for improving individual practices (horizontal movement), PBRNs now find themselves at the multidimensional crossroads of patient-centeredness and community/population health (vertical movement). This practice-based research theme issue of the Journal of the American Board of Family Medicine provides a rich, cross-sectional synopsis of PBRN activities encompassing T2 translation, core practice-based research, implementation and dissemination research, community practice, and contributions to health care policy.(J Am Board Fam Med 2014;27: 725-729.)

Looking through old practice-based research network (PBRN) materials to prepare for a talk at the 20th Anniversary Oklahoma Physicians Resource/ Research Network (OKPRN) Convocation this year, I found a promotional CD that we created more than 10 years ago. Remembering some excellent sound-bites, I fast-forwarded to the middle of the recruitment video, and there, among strangely bulky computer monitors, towering stacks of patient charts, and thick PalmPilots, was one of our champion clinicians, Dr. Scott Stewart from Shawnee, Oklahoma, uttering the enduring words that became the guiding principle of our PBRN: "I like working with OKPRN because they do research that matters in my practice."

Scott's clear, instinctive understanding of a PBRN stayed with me and guided me over the years every time I was tempted to look at re-

Submitted 5 September 2014; revised 5 September 2014; accepted 5 September 2014.

From the Department of Family and Preventive Medicine, University of Oklahoma, Oklahoma City.

Funding: none.

Conflict of interest: $\mathrm{ZN}$ is an editorial board member of the 7ABFM.

Corresponding author: Zsolt J. Nagykaldi, PhD, Department of Family and Preventive Medicine, University of Oklahoma, 900 NE 10th St, Oklahoma City, OK 73104 (E-mail: znagykal@ouhsc.edu). search only from my academic rolling chair. OKPRN has not been alone on this multidecade journey toward mutual growth from the early "ASPN Days," when building an "enduring infrastructure" of primary care research was initiated, against all odds, in the United States. The past 10 to 15 years have seen an amazing and hopeful transformation and maturation of PBRNs in every sense. Small, unrecognized groups of enthusiastic family doctors and researchers working on a "shoestring budget" were gradually joined by wellestablished, multidisciplinary teams of health professionals from a variety of countries filling large conference rooms. Difficult way-searching on the never-traveled road of practice-based research has been replaced by confident application of systematic and innovative methods that PBRNs created for themselves to reach ever farther and answer ever more difficult but relevant questions. The early lack of support for PBRN research gave way to multimillion-dollar funding opportunities when even the most prestigious academic institutions took notice of PBRNs and the potential of their work.

The journey of PBRNs has just started, but this 2014 annual theme issue of the Fournal of the American Board of Family Medicine is already a testament 
Figure 1. The pipeline of research translation. Dark gray boxes represent domains of practice-based research. T1 through T4 represent research translation steps. CER, comparative effectiveness research; PCOR, patient-centered outcomes research; QI, quality improvement.

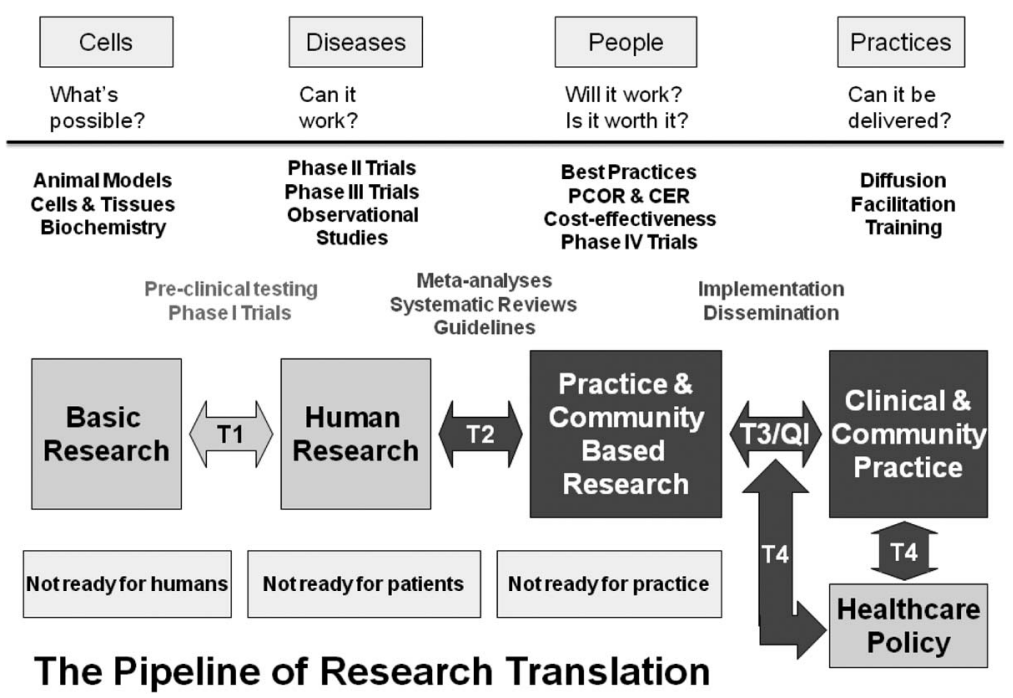

to the resiliency, ingenuity, relevance, and substantial impact of PBRNs on "research that matters in practice." One of the defining characteristics of PBRNs is their ability to operate across a wide range of the bidirectional "pipeline of research translation" (Figure 1), from performing clinical trials to informing health care policy. While the historic paradigm of clinical research was usually limited to academic publication of human studiesand translation often meant turning basic science findings into clinical trials (T1 translation) PBRNs today continually encourage funders, researchers, and end users (clinicians and patients) to open their horizon to at least 4 steps of research translation. T2 research translation converts the results of clinical trials conducted under ideal conditions into interventions that can be tested in "messy" real-world practices and communities. These practices and communities (the heart of PBRNs) can be conceptualized as "experimental farms." They are "out in the wild" but are specifically prepared to become pioneer testing sites of emerging innovations not entirely ready for fullscale implementation. T3 translation, which can also be viewed as quality improvement, applies systematic methods to move community-based beta tests into general practice through dissemination and implementation (D\&I) research. Last, through ongoing interaction between practice and policy, T4 research translation can facilitate the inculcation of state-of-the-art practices into health care policy. Development of effective translational approaches requires significant experimentation with new or innovatively combined research methods and theoretical frameworks. Some areas of translation-for example, T3, which integrates research and quality improvement-necessitate a paradigm change. Not surprisingly, many articles (7 of 18) in this practice-based research theme issue focus on the expansion of research methodology and improvements in theory.

\section{T2 Translation}

Highlighting the translational linkage between classic clinical trials and practice-based research, Elder and $\mathrm{Munk}^{2}$ report the application of the PRECIS model (developed by the CONSORT Work Group) to inform and refine a Kentucky Ambulatory Network study. The PRECIS wheel is a summative visual representation of 10 measures indicating domains of the pragmatism or effectiveness of clinical trials. While it is certainly a significant step in the right direction, PRECIS does not directly address the practice-based relevance of the research question-the feasibility of the intervention and the total cost of the implementation in realworld settings. PBRNs could further refine PRECIS to include these and other measures important for the bidirectional exchange between research and practice. 


\section{Practice and Community-Based Research}

A number of articles in this issue (9 of 18) showcase classic PBRN research projects. Robitaille et al, ${ }^{3}$ from Quebec City, demonstrate an interesting method for recruiting study participants through the engagement of clinician-patient dyads. This approach is rooted in established PBRN research experience for effective recruitment and study management (eg, study site champions, relationship building, and practice facilitation). Improving the rigor of PBRN research while aligning it with the mission and vision of PBRNs has always been important. Dolor et $\mathrm{al}^{4}$ describe a new toolkit that contains expert recommendations for conducting collaborative clinical trials in PBRNs. External validity (generalizability to practice) is a definitive strength of PBRN research. To complement the above toolkit, Spears et $\mathrm{al}^{5}$ compiled communitycentered approaches to recruiting diverse and representative samples of participants based on the responses of PBRN directors to a cross-sectional survey. The 7 recommended strategies are called the "cycle of trust" to underscore the pivotal importance of maintaining trusting relationships to grow the "experimental farm."

As one of the most exciting possibilities in 21stcentury health care, health information technology has played a significant role in PBRN research since its earliest days. Of the 3 health information technology studies in this issue, 2 represent core practice-based research. A second team from the Kentucky Ambulatory Network (Riddell et $\mathrm{al}^{6}$ ) presents 8 themes, derived from qualitative research, of best practices for achieving "meaningful use" in primary care practices working with a regional extension center. These practical recommendations add to the rapidly growing evidence on effective EHR implementation. Bauer et $\mathrm{al}^{7}$ used survey research methods to provide interesting and important insights into the exponentially growing but often elusive world of mobile health (mHealth) technologies and their use in health care. They showed that up to one third of primary care patients may use mHealth tools for searching information and tracking and managing personal health, but the medical profession is significantly behind the curve in terms of acceptance and strategic utilization. Substantially more research is needed to solidify our understanding of the most appropriate designs and efficacious implementation of mHealth technologies. A good example of community-based comparative effectiveness research is set forth by Green et al, ${ }^{8}$ who randomized patients with a positive fecal occult blood test or sigmoidoscopy to a nurse care coordination intervention with registrybased reminders or usual care. Although the trial did not show significant differences between groups, the findings will inform a future, more optimally powered study. Tyler and Werner ${ }^{9}$ share a distinct "prenatal history" of a newly developing community-based PBRN that focuses on developmental disabilities, demonstrating how CTSAfunded shared resources can energize and involve the larger community in practice-based research. Although best practices for handling laboratory test results in primary care have been identified before ${ }^{10}$ West et $\mathrm{al}^{11}$ revisit this topic in the current environment of electronic tracking systems and compare practices with and without electronic health records (EHRs). Not surprisingly, few practices implemented an effective EHR-based tracking system because of technical difficulties and mistrust, resulting in practice-based workarounds. Finally, a research letter by Cardinali et al ${ }^{12}$ underscores the importance of measuring rates of underinsurance, even after the introduction of the Affordable Care Act.

\section{T3 Translation (Quality Improvement Research)}

The traditional research paradigm considered improvement in the quality of care unscientific or even unacademic. However, this notion became obsolete with the gradual integration of D\&I into mainstream PBRN research. Numerous PBRN studies now leverage adaptations of evidence-based, formerly industrial quality improvement methods. An excellent opinion article on the strategic role of D\&I in PBRN research translation is presented by Heintzman et al. ${ }^{13}$ They propose that traditional D\&I researchers and PBRNs are natural partners and their professional exchange can enhance the quality of pragmatic studies in "community laboratories." Another good example of implementation research comes from the OCHIN PBRN. Angier et $\mathrm{al}^{14}$ deployed geographic information system technology to visualize EHR data on insurance information in a granular fashion. They demonstrated significant geographical variation in insurance rates and variation of coverage by age and 
household income. This approach will allow them to systematically target OCHIN practices with tailored outreach interventions.

The extension of the work of PBRNs from network practices into the community was conceptualized by Werner and Stange ${ }^{15}$ in a thought-provoking theoretical commentary. Their article echoes what seems to be a recent evolutionary shift in PBRN research. While the first decades of PBRN research generated a substantial body of evidence for improving individual practices (moving on a horizontal structural plane), PBRNs now find themselves at the multidimensional crossroads of patient-centeredness and community/population health (ascending on a vertical plane). Several visions emerged to help PBRNs respond to this higher challenge. In this theme issue, Werner and Stange suggest that PBRNs should become "praxis-based research networks" that create an array of partnerships with community organizations. In the process, PBRNs could extend their role to include community engagement and innovation diffusion by turning into "multistakeholder learning organizations that seek to improve community health." However, another, somewhat different approach could also be proposed that would keep the scope of PBRN activities within the "experimental farm" through strategic linkages to the evolving Primary Care Health Extension Program (PCEP). ${ }^{16}$ This approach could organizationally separate the generation and testing of evidence (a more scientific activity) from the diffusion of innovations emanating from PBRNs (a more structural or systemic activity).

\section{Clinical and Community Practice}

Two articles explore programs in community primary care practices. An international outlook at a community-based screening program is provided by van Mourik et $\mathrm{al}^{17}$ from Utrecht, the Netherlands. The 2-step program included a near-home prescreening followed by an office-based, in-depth diagnostic battery for community-dwelling frail individuals; the program uncovered a significant number of patients with previously undiagnosed heart failure or chronic obstructive pulmonary disease. However, whether tailoring patient treatment would result in improved long-term outcomes is not yet known. Ravi et al ${ }^{18}$ looked at outcomes of intrauterine device use during a 6-month follow-up period among adolescents and adults in a retrospective cohort study of federally qualified health centers in New York City. Outcomes included postinsertion experience, device discontinuation, and sexually transmitted infections. Adolescents had a higher rate of postinsertion patient-initiated follow-up for adverse reactions or removal requests compared with adults.

\section{T4 Translation}

Partnering with professional organizations, PBRNs take increasing responsibility for informing health care policy with their uniquely practical insights. Their closeness to the reality of daily practice is extremely useful to help anchor the research agenda in the needs of patients, clinicians, and communities. A forward-looking policy insight is provided in this issue by Dr. Larry Green, who warns us about the growing temptation to inconsiderately use "big [bad] data" to meet the new challenges of health care. He proposes instead that we redesign our clinical data architecture around the attributes of primary care: accessibility, continuity, comprehensiveness, patient-centeredness, coordination, partnership, integration, and accountability. ${ }^{19}$ Etz et $\mathrm{al}^{20}$ bring the necessity of health care paradigm change to light in a wellarticulated policy brief. They draw a sharp contrast between traditional academic research that favors disease-focused, slowly incremental, often more theoretical work and PBRN research that facilitates patient and practice goal-directed, systemic, and disruptive innovations that offer viable solutions to everyday problems. On a concordant note, Doohan et $\mathrm{al}^{21}$ reflect on the history and future of family medicine from a multigenerational perspective. Their article clearly illustrates the co-emergence of family medicine and practice-based research as they share an ultimate goal: to create a strong primary health care system that specializes in the entire person and operates in communities of solutions.

In summary, the rich, cross-sectional sample of practice-based research presented in this issue celebrates the many milestones passed by practicebased research networks. At the same time it offers a glimpse at their rising potential to shape the future of health care in the United States and beyond. PBRNs will accomplish their mission by continually refocusing the goal of research on the most effective approaches to improving the well-being of individuals and communities. 


\section{References}

1. Green LA, Hickner J. A short history of primary care practice-based research networks: from concept to essential research laboratories. J Am Board Fam Med 2006;19:1-10.

2. Thorpe KE, Zwarenstein M, Oxman AD, et al. A pragmatic-explanatory continuum indicator summary (PRECIS): a tool to help trial designers. J Clin Epidemiol 2009;62:464-75.

3. Robitaille H, Légaré F, Tre G. A systematic process for recruiting physician-patient dyads in practicebased research networks (PBRNs). J Am Board Fam Med 2014;27:740-9.

4. Dolor RJ, Schmit KM, Graham DG, Fox CH, Baldwin LM. Guidance for researchers developing and conducting clinical trials in practice-based research networks (PBRNs). J Am Board Fam Med 2014;27: 750-8.

5. Spears W, Tsoh JY, Potter MB, et al. Use of community engagement strategies to increase research participation in practice-based research networks (PBRNs). J Am Board Fam Med 2014;27:763-71.

6. Riddell MC, Sandford KG, Johnson AO, Steltenkamp C, Pearce KA. Achieving meaningful use of electronic health records (EHRs) in primary care: proposed critical processes from the Kentucky Ambulatory Network (KAN). J Am Board Fam Med 2014;27:772-9.

7. Bauer AM, Rue T, Keppel GA, Cole AM, Baldwin LM, Katon W. Use of mobile health (mHealth) tools by primary care patients in the WWAMI region Practice and Research Network (WPRN). J Am Board Fam Med 2014;27:780-8.

8. Green BB, Anderson ML, Wang CY, et al. Results of nurse navigator follow-up after positive colorectal cancer screening test: a randomized trial. J Am Board Fam Med 2014;27:789-95.

9. Tyler CV, Werner JJ. Community-engagement strategies of the Developmental Disabilities Practice-Based Research Network (DD-PBRN). J Am Board Fam Med 2014;27:831-8.

10. Mold JW, Cacy DS, Dalbir DK. Management of laboratory test results in family practice. An OKPRN study. Oklahoma Physicians Resource/Research Network. J Fam Pract 2000;49:709-15.

11. West DR, James KA, Fernald DH, Zelie C, Smith ML, Raab SS. Laboratory medicine handoff gaps experienced by primary care practices: a report from the Shared Networks of Collaborative Ambulatory Practices and Partners (SNOCAP). J Am Board Fam Med 2014;27:796-803.

12. Cardinali G, Rhyne RL, Fleg A, et al. Underinsurance before the implementation of the affordable care act: from the Research Involving Outpatient Settings Network (RIOS Net). J Am Board Fam Med 2014;27:855-7.

13. Heintzman J, Gold R, Krist A, Crosson J, Likumahuwa S, DeVoe JE. Practice-based research networks (PBRNs) are promising laboratories for conducting dissemination and implementation research. J Am Board Fam Med 2014;27:759-62.

14. Angier H, Likumahuwa S, Finnegan S, et al. Using geographic information systems (GIS) to identify communities in need of health insurance outreach: an OCHIN practice-based research network (PBRN) report. J Am Board Fam Med 2014;27: 804-10.

15. Werner JJ, Stange KC. Praxis-based research networks: an emerging paradigm for research that is rigorous, relevant, and inclusive. J Am Board Fam Med 2014;27:730-5.

16. Phillips RL Jr, Kaufman A, Mold JW, et al. The primary care extension program: a catalyst for change. Ann Fam Med 2013;11:173-8.

17. van Mourik Y, Bertens LCM, Cramer MJ, et al. Unrecognized heart failure and chronic obstructive pulmonary disease (COPD) in frail elderly detected through a near-home targeted screening strategy. J Am Board Fam Med 2014;27:811-21.

18. Ravi A, Prine L, Waltermaurer E, Miller N, Rubin SE. Intrauterine devices at six months: does patient age matter? Results from an urban family medicine federally qualified health center (FQHC) network. J Am Board Fam Med 2014;27:822-30.

19. Defining primary care: an interim report. Washington, DC: National Research Council; 1994.

20. Etz RS, Hahn KA, Gonzalez MM, Crabtree BF, Stange KC. Practice-based innovations: more relevant and transportable than NIH-funded studies. J Am Board Fam Med 2014;27:738-9.

21. Doohan NC, Endres J, Koehn N, et al. Back to the future: reflections on the history of the future of family medicine. J Am Board Fam Med 2014;27: $839-45$. 